\title{
Liberdade decisória do médico e compreensão pelo paciente: o dever recíproco de informação como pressuposto fundamental
}

Libertad decisoria del médico y comprensión por el paciente: el deber recíproco de información como presupuesto fundamental

Decision-making freedom of the doctor and patient understanding: the reciprocal duty of information as a fundamental presupposition

Ana Thereza Meirelles Araújo ${ }^{1}$ Lyellen Silva Fernandes ${ }^{2}$

\begin{abstract}
Resumo
Objetivo: esta pesquisa busca investigar, por intermédio de uma análise bibliográfica, a importância do ato de informar no cerne da relação médico-paciente, tendo em vista que esse dever é direcionado às duas partes: tanto aos profissionais de saúde, quanto aos pacientes. Metodologia: foi realizada uma pesquisa predominantemente bibliográfica, que visou interpretar as categorias sociais, normativas e morais para se alcançar uma conclusão, evidenciando uma abordagem de natureza qualitativa. Resultados: o dever de informação é pressuposto ao exercício da autonomia. Conclusão: o paciente tem o direito de ter à disposição todo e qualquer dado relevante para que possa, livre e conscientemente, decidir, bem como o médico também tem o direito de ser munido de toda informação relacionada ao histórico da doença vivenciada pelo paciente.
\end{abstract}

\section{Palavras-chave}

Bioética. Autonomia. Informação. Compreensão.

\begin{abstract}
Objective: this research seeks to investigate, through a bibliographic analysis, an importance of the act of informing at the heart of the doctor-patient relationship, considering that this duty is directed to both parties: both health professionals and patients. Methodology: a predominantly bibliographic research was conducted, which aimed to interpret as social, normative and moral categories in order to reach a conclusion, showing a qualitative approach. Results: the duty of information is presupposed to the exercise of autonomy. Conclusion: the patient has the right to have contact with all relevant data available so that he can freely and consciously decide, as well as the doctor also has the right to be provided with all information related to the history of the disease experienced by the patient.
\end{abstract}

\section{Keywords}

Bioethics. Autonomy. Information. Understanding.

\section{Resumen}

Objetivo: esta investigación busca indagar, a través de un análisis bibliográfico, la importancia del acto de informar en el corazón de la relación médico-paciente, considerando

\footnotetext{
${ }^{1}$ Pós-Doutoranda em Medicina, Universidade Federal da Bahia, Salvador, Bahia, Brasil; doutora em Direito, Universidade Federal da Bahia, Salvador, Bahia, Brasil; professora, Universidade Católica do Salvador (UCSal), Salvador, Bahia, Brasil. https://orcid.org/0000-0001-9623-6103. E-mail: anatherezameirelles@gmail.com

2 Especialista em Direito Público, Faculdade Unyleya, Brasília, Distrito Federal, Brasil; bacharel em Direito, Faculdade Baiana de Direito e Gestão, Salvador, Bahia, Brasil; advogada. https://orcid.org/0000-0001-8783-8663. E-mail: lyellenfernandes@gmail.com
} 
que este deber está dirigido a ambas partes: tanto a los profesionales de la salud como a los pacientes. Metodología: se realizó una investigación predominantemente bibliográfica, la cual tuvo como objetivo interpretar categorías sociales, normativas y morales para llegar a una conclusión, mostrando un enfoque cualitativo. Resultados: se presupone el deber de información para el ejercicio de la autonomía. Conclusión: el paciente tiene derecho a disponer de todos y cada uno de los datos relevantes para que pueda decidir libre y conscientemente, así como el médico también tiene derecho a que se le facilite toda la información relacionada con la historia de la enfermedad vivida por el paciente.

\section{Palabras clave}

Bioética. Autonomía. Información. Comprensión.

\section{Introdução}

Atualmente, o direito à informação vem ganhando contornos relevantes no âmbito de várias relações sociais. Esta pesquisa busca investigar, por intermédio de uma análise bibliográfica, a importância do ato de informar no cerne da relação médico-paciente, tendo em vista que esse dever é direcionado às duas partes: tanto aos profissionais de saúde, quanto aos pacientes. Tem como pressuposto evidenciar que apenas trazer a informação em si não satisfaz as necessidades de uma relação segura, sendo de suma importância verificar também a presença da compreensão dos sujeitos envolvidos $(1,2)$.

Pode-se atentar para a importância desta pesquisa na medida em que não somente os profissionais de saúde possuem um papel valoroso, mas também os pacientes, sujeitos que devem participar do processo de construção da relação ainda que, muitas vezes, destituídos de conhecimentos técnicos e científicos. Resulta disso a necessidade de abordar a medida de incidência da autonomia, tanto do médico quanto do paciente, no cerne da relação que desenvolvem (2).

Pretendeu-se fincar a importância da conjugação dos dois elementos -informação e compreensão - como basilares à formação adequada da relação entre médicos e pacientes, em consonância à legislação ordinária e aos comandos disciplinares do Conselho Federal de Medicina $(2,3,4)$.

\section{Metodologia}

Trata-se de revisão bibliográfica sobre a importância do dever de informar na relação médico-paciente que buscou, por meio de livros, artigos, capítulos e legislação, consubstanciar um estudo qualitativo. 
Efetuou-se um levantamento bibliográfico de artigos obtidos em diferentes sites, como a Revista Bioética do Conselho Federal de Medicina ${ }^{3}$, bibliotecas eletrônicas científicas online, como SciELO ${ }^{4}$, e repositórios de trabalhos científicos, como o repositório da Universidade Católica de Brasília ${ }^{5}$ e da Universidade Federal do Rio Grande do Sul. ${ }^{6}$

Selecionou-se artigos da Revista Bioética do Conselho Federal de Medicina e publicações do Conselho Nacional de Pesquisa e Pós-graduação em Direito (CONPEDI) ${ }^{7}$ que discorressem sobre o tema informação na relação médico-paciente e autonomia. Também se buscou referenciais em bioética, o que incluiu autores nacionais e estrangeiros, dentre os quais se pode citar Ferrer JJ; Álvarez JC e Beauchamp e Childres que possuem trabalhos científicos relacionados à liberdade decisória e à compreensão na relação médicopaciente.

A pesquisa tem natureza teórica e foi estruturada a partir do pressuposto de que a busca pela conformação adequada do dever de informação na relação médico-paciente é o resultado da averiguação de premissas, como a ideia de compreensão.

\section{A construção da relação médico-paciente e os paradigmas de hoje}

A relação médico-paciente, assim como toda e qualquer relação, vem sofrendo mudanças. Tais alterações apontam para um panorama que agrega uma medicina complexa, acentuada por um espectro significativo de informações científicas, reveladas nas descobertas de novas doenças e novos protocolos terapêuticos, assim como a mudança no perfil do paciente, cada vez mais munido de informações.

Robert Veatch, do Instituto Kennedy de Ética da Universidade Georgetown, nos Estados Unidos, (1) apontou, em 1972, quatro modelos de relação médico-paciente. O modelo sacerdotal ou tradicional, baseado na tradição hipocrática, na qual o médico assume uma posição paternalista diante do paciente, alicerçado no fundamento da beneficência, sendo que a decisão tomada pelo médico independente do entendimento do paciente. $\mathrm{O}$ modelo engenheiro concentra o poder decisório nas mãos do paciente, cabendo ao profissional assumir o papel de executor das ações propostas por aquele. No modelo colegial, não há diferença entre os papéis do médico e do paciente no contexto da relação.

\footnotetext{
${ }^{3}$ https://revistabioetica.cfm.org.br/index.php/revista_bioetica

4 https://scielo.org/

5 https://repositorio.ucb.br:9443/jspui/

6 https://lume.ufrgs.br/handle/10183/12730

7 https://www.conpedi.org.br/
} 
E, por fim, o modelo contratualista, no qual o médico preserva a sua autoridade, enquanto detentor de conhecimentos e habilidades específicas, assumindo a responsabilidade pela tomada de decisões técnicas. Nesse modelo, o paciente possui papel participativo no processo de tomada de decisões, exercendo sua atuação em conformidade aos seus valores morais e pessoais. Há efetiva troca de informações e a tomada de decisão pode ser de médio ou alto envolvimento, tendo por base o compromisso estabelecido entre as partes envolvidas (1). O modelo contratualista hoje descortina o caminho da relação médicopaciente, na medida em que é necessário reconhecê-la também como uma relação de natureza jurídica (1).

O modelo sacerdotal ou tradicional, caracterizado pela medicina paternalista, manifesta-se a partir do conflito entre dois princípios da bioética principialista: a autonomia e a beneficência. Beneficência, no seu significado filosófico moral, quer dizer fazer o bem (2). De acordo com Beauchamp e Childress (3), o princípio da beneficência prevê atitudes positivas para estimular o bem e realização dos demais. Compõem o princípio da beneficência a beneficência positiva - agir de forma benéfica em prol de outrem - e o princípio da utilidade - sopesar os benefícios e os inconvenientes para se chegar à melhor decisão (3). Entende-se por beneficência uma ação humana positiva para beneficiar os indivíduos. Já o princípio da autonomia significa a capacidade que as pessoas possuem de se autodeterminar, livres de influências externas (3).

Historicamente, foi ensinado aos médicos que a saúde de seus pacientes deveria ser sempre reestabelecida e a enfermidade a qual se procurava a cura deveria ser eliminada, fazendo-o, muitas vezes, sofrer com as patologias geradas pela doença. Entretanto, hoje, deve-se repensar a ótica antes perseguida, na medida em que se deve ter em mente que nem toda doença tem cura e a decisão do sujeito enfermo deve ser considerada (4). É justamente essa guinada na percepção - o que de fato compete à medicina - que facilita a compreensão das novas características dessa relação.

O paternalismo pode ser conceituado como a interferência do profissional de saúde sobre a vontade de pessoa autônoma, justificada por diversos motivos, tais como bem-estar, necessidades ou valores da pessoa que está sendo submetida ao tratamento. Existente na interação médico-paciente, o paternalismo foi concebido como uma característica relacional básica, que diferencia o contrato médico de outras relações contratuais, sendo muitas vezes reconhecido como um privilégio terapêutico (2). 
Por não ser uma exclusividade na medicina, fala-se também do paternalismo econômico, governamental, jurídico, laboralista, familiar e pedagógico, entre outros (2). O paternalismo manifesta características comuns: superproteção, autoritarismo, inibição, infantilismo, conduzindo, assim, todas elas a uma conjuntura anômala daquela que o paciente, empregado, cidadão poderia se encontrar (2). É importante, desde já, frisar que este pasernalismo historicamente concebido como inerente à relação não encontra compatibilidade com o pleno exercício da autonomia do enfermo, hoje reconhecida juridicamente.

Com o advento do capitalismo, mais precisamente com a Revolução Industrial, não somente houve uma exacerbação nas desigualdades sociais, como também se verificou a separação dos meios de produção dos seus produtores. A relação médico-paciente passou a lidar com uma nova conjuntura: as demandas médicas tornaram-se cada vez mais expressivas e o sistema de saúde, que envolve a saúde pública e a suplementar, não consegue atender com adequação nenhuma das duas partes envolvidas, tornando-se incipiente para os pacientes, e, por vezes, inóspito para os médicos (5).

Como assevera Alvaro Angelo Sales (5), "na sociedade ocidental capitalista, os ritos de passagem estão sendo extintos ou artificializados", e isso contribui para que a relação em voga se torne, também, líquida. A "modernidade líquida", de Zygmunt Bauman (6), evidencia, por meio de metáforas, como as relações humanas estão alicerçadas na superficialidade, no imediatismo, na falta de profundidade e conteúdo.

Surge, então, uma nova conjuntura no âmbito das relações de saúde em geral. A medicina estritamente paternalista dá ensejo a uma nova perspectiva: a medicina que reconhece e valoriza a autonomia do paciente.

Autonomia possui sua raiz no termo grego auto (próprio) e nomos (lei, regra, norma). Exprime o sentido de autogoverno, autodeterminação do ser humano de tomar decisões que influenciam sua vida, sua saúde, sua integridade físico-psíquica, suas relações sociais. Refere-se à capacidade de o ser humano decidir o que é bom, ou o que é seu bem-estar (2). Acrescente-se, no entanto, a necessidade de apartar os conceitos de capacidade e de autonomia, tendo em vista que servem a perspectivas pragmáticas distintas.

Autônoma é aquela pessoa que possui liberdade de pensamento e encontra-se livre de coações internas ou externas para escolher entre as alternativas que lhe são apresentadas. Para que se pratique ações autônomas, faz-se necessário que o paciente, diante da oferta de alternativas, exerça seu poder de escolha de acordo com seus 
conhecimentos de vida. Se não há liberdade de pensamento, ou, ainda, se não há a liberdade de agir conforme a alternativa ou opção desejada, a ação empreendida não pode ser concebida como autônoma (2).

Certas variáveis influenciam na caracterização da autonomia, quais sejam: estruturas biológicas, socioculturais, psíquicas, dentre outras. Há pessoas que, de forma transitória ou permanente, têm sua autonomia reduzida, como as crianças; deficientes mentais; pessoas em estado de agudização de transtornos mentais; indivíduos sob intoxicação exógena, que se encontram sob efeito de drogas, em estado de coma etc. (2).

Reconhecer a autonomia do paciente é respeitar sua vontade, anuir com sua capacidade de se autogovernar e legitimar sua participação ativa no processo terapêutico (7). Essa realidade é uma prerrogativa reconhecida por lei e demanda a necessidade de concretização (8-9).

Deve-se esclarecer que o princípio da beneficência e o princípio da autonomia podem pautar a conduta do profissional de saúde, conduzindo-o em situações de conflito. Um comando principiológico não deve anular o outro, ao contrário, devem conviver harmoniosamente em prol da necessidade de garantir uma relação exitosa.

A relação médico-paciente, hoje, no contexto de reconhecimento da autonomia do sujeito, enfrenta paradigmas outros, como a evolução dos recursos tecnológicos disponíveis (10). O uso da tecnologia, como uma realidade ínsita à relação, pode trazer benefícios importantes, mas precisa ser pensada não como um instrumento para fragmentar ou destituir a relação direta, presencial e humana entre os sujeitos envolvidos (10).

José Marques Filho e William Saad Hossne (10) concluíram que o fato de o paciente consultar a internet pode levar, por um lado, à melhora do diálogo com o médico, à facilitação do estabelecimento de pontes e à maior atenção do profissional ao seu paciente. Por outro lado, pode originar resistências e dificuldades, se o médico sentir que está sendo checado pelo paciente quanto ao seu conhecimento e atualização, podendo gerar uma situação de desconfiança mútua (10). Assim, competirá ao profissional ressignificar o seu papel perante o paciente, pois cabe ao médico o esclarecimento técnico de um quadro clínico e a aferição adequada de um diagnóstico.

Essa relação obteve consideráveis mudanças no decorrer dos séculos, ensejando o reconhecimento do potencial decisivo do paciente. Todavia, há também um aumento no desgaste na relação, o que é confirmado pelo ascendente número de ações judiciais, sem apontar a parcela de culpa de cada parte envolvida. Sabe-se, previamente, que a relação 
posta em foco pressupõe deveres de ambas as partes e deve estar alicerçada nessa prerrogativa, para que os envolvidos se mantenham irmanados pelo desejo de sanar ou paliativar a patologia identificada.

\section{A complexidade da medicina e as múltiplas demandas terapêuticas}

A palavra risco é oriunda do italiano resicare, que significa ousar (11). O senso comum aponta que risco está relacionado à possibilidade, maior ou menor, de algo indesejável ocorrer. O dimensionamento do risco está vinculado à possibilidade de ocorrência do evento indesejável em função da atividade que é exercida.

Ulrich Beck (12) cunhou a expressão sociedade de risco, em 1980, defendendo que o processo de modernização fomenta a configuração de uma sociedade que distribui riscos e anseia por segurança. O risco pode ser compreendido pelas ameaças projetadas no futuro e que possuem o poder de causar destruições em proporções alarmantes, incapazes de serem remediadas (12). O fato de o risco ser algo prospectado para o futuro - na sociedade de risco o passado não possui força vinculante - faz com que o objetivo seja nos tornar ativos e conscientes hoje para evitar ou mitigar os problemas vindouros (12).

Ulrich Beck (12) frisou que o risco não é algo que se manifestou apenas na sociedade moderna; em tempos passados, o risco também existia, porém, de forma distinta. O risco era compreendido por riscos pessoais, locais, diferentemente de hoje, quando o conceito de risco é entendido como riscos globais, capazes de afetar toda a humanidade, situações que estão fora do controle expressivo do ser humano (13).

A atividade médica traz consigo riscos inerentes, seja pelas incertezas de qual tratamento optar, pelos riscos que cada opção terapêutica possa agregar, pelo desconhecimento das consequências de um determinado tratamento ainda pouco usado, pelos efeitos colaterais do tratamento escolhido, por sua complexidade e relação direta com os pacientes, acentuada pelo acesso direto à informação pela internet.

A medicina não é uma ciência exata. A forma de abordagem e a terapêutica varia conforme o profissionale o organismo do ser humano se diferencia de uma pessoa para a outra, respondendo, de forma diversa a um mesmo tratamento (11). Por ser uma relação formada por variáveis complexas, é difícil prever com exatidão a consequência exata de algum procedimento, portanto, convêm avaliar alguns riscos inerentes à atividade médica e como eles se apresentam. Conceber a medicina como uma atividade que naturalmente 
agrega riscos importantes é estabelecer um pressuposto necessário à sua compreensão adequada.

O ambiente de trabalho também favorece a interpretação da atividade médica como de risco. As más condições de trabalho, como a sobrecarga de atividades semanais, e as condições físicas do estabelecimento podem influenciar a conduta do profissional (14).

Pode-se ter em conta que a medicina, hoje, agrega recursos terapêticos transformadores, capazes de curar ou de melhorar a qualidade de vida de sujeitos portadores de diversas enfermidades. Dentre as inúmeras transformações, pode-se citar como exemplo a impressão em 3D, que permite a reprodução fiel de cópias de tecidos e órgãos, prática que proporciona uma multiplicação de tecidos para incalculáveis finalidades farmacológicas e médicas (15).

\section{O dever de informação como elemento fundamental}

O fornecimento de informações equivocadas ou a não informação tem o condão de viciar a relação médico-paciente, que deve ser fundada no dever de informar. Informar é uma obrigação do médico, como também do paciente, e agrega a tarefa de fornecer todos os elementos possíveis e necessários em prol da obtenção de um resultado exitoso.

\section{O dever de informação pelo médico como pressuposto à autonomia do paciente}

Como apontado anteriormente, a visão paternalista da medicina foi substituída pela perspectiva na qual, não só o médico tem o poder de deliberar sobre as decisões a serem tomadas, mas, também, o paciente autônomo, que possui papel fundamental na consecução de uma relação segura $(7,8,9)$.

Autonomia significa a capacidade das pessoas de se autodeterminar sem a influência de agentes externos. É composta por duas condições: liberdade externa - o indivíduo deve estar desprendido de influências externas - e a liberdade interna - capacidade que o indivíduo tem de agir intencionalmente. O ser humano autônomo age de acordo com suas convicções e escolhas; entretanto, indivíduos com autonomia minimizada são controlados por outras pessoas e possuem a capacidade de deliberar sobre suas próprias vidas diminuídas (16).

Para Beauchamp e Childress (16), uma ação é provida de autonomia se o indivíduo age intencionalmente, com compreensão e sem influências externas que determinem ou controlem sua ação. 


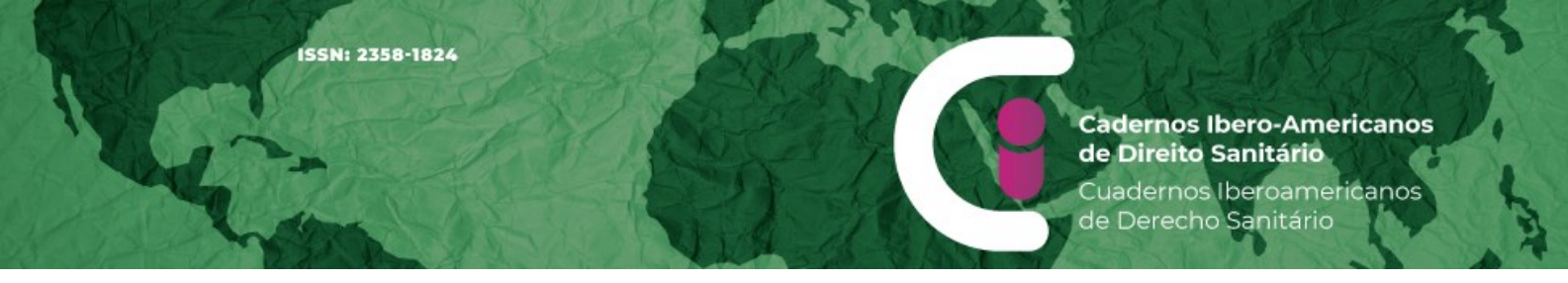

Outros autores defendem que a autonomia não seria apenas mais um princípio bioético, mas, também, uma característica do ser humano, que lhes permitiria o autogoverno para decidirem sobre suas vidas e segundo suas escolhas (3). Segundo Beauchamp e Childress, o princípio de respeito à autonomia vai além da obrigação de não-intervenção em assuntos pessoais, inclui, ainda, a obrigação de manter a capacidade de escolha autônoma em pessoas que estejam com receios e outras condições que debilitem ou interrompam sua capacidade de agir autonomamente. Para isso, o esclarecimento do paciente e o efetivo relacionamento de mútua confiança são fundamentais (17).

O princípio da autonomia tornou-se símbolo do direito moral dos pacientes decidirem sem coerções, tendo o poder de modificar a relação médico-paciente e alterar as relações verticais em relações harmoniosas e proporcionais entre sujeitos autônomos.

O reconhecimento no enfermo de sua condição de sujeito, protagonista e usuário crítico, livre e responsável, dos serviços de saúde, restitui-lhe competência moral, e rompe com o paternalismo e o absolutismo que transformam o cliente em receptáculo de ordens. (18)

No art. 22 do Código de Ética Médica (21), é vedado ao médico "efetuar qualquer procedimento médico sem o esclarecimento e o consentimento prévios do paciente ou de seu representante legal, salvo em iminente perigo de vida". O art. 24 prevê, também, que é vedado aos profissionais de medicina limitar o direito de os pacientes decidirem livremente sobre sua pessoa ou sobre seu bem-estar (art. 48), princípio que, com relação às pesquisas médicas, é reforçado pelos arts. 123 e 124 (2). Por seu turno, os arts. 31 e 34 robustecem o direito de o paciente decidir livre e conscientemente sobre a execução de práticas diagnósticas e terapêuticas, e o seu direito à informação sobre o diagnóstico, o prognóstico, os riscos e objetivos do referido tratamento (19).

O respeito à autonomia reclama que se tolerem crenças incomuns e escolhas das pessoas, desde que não constituam ameaça a outros indivíduos ou à coletividade. Em suma, ressalta-se que o corpo, a dor, o sofrimento, a doença é algo ligado à pessoa (2).

Considerado um dos pilares da bioética, o princípio da autonomia relaciona-se com o poder de informação que o paciente possui. Um paciente autônomo possui liberdade de escolha racional, ou seja, o direito de se autodeterminar (18). Para configurar um paciente autônomo, faz-se mister a colaboração do profissional de medicina, fornecendo-lhe a informação adequada e suficiente para sua tomada de decisão consciente. A informação é considerada o pilar central das decisões autônomas do paciente, necessária para que ele 
Constata-se a relevância da boa-fé na relação médico-paciente. As informações disseminadas nessa conjuntura devem ser suficientes para se ter uma relação segura, confiável, baseada na boa-fé objetiva, tendo em vista que esse princípio nada mais é que um modelo de comportamento social que aproxima os indivíduos de um conceito ético de proceder da forma mais correta possível (22).

O dever de informação pelo paciente como pressuposto à decisão adequada do médico

Hodiernamente, o paciente assumiu uma posição atuante e espera que a sua individualidade seja assegurada.

Por isso, o paciente autônomo tem o dever de fornecer ao profissional de medicina toda e qualquer informação que possa ser relevante para uma adequada tomada de decisão sobre as opções disponíveis com relação à sua patologia (boa-fé objetiva). Da mesma forma, possui o direito de consentir ou recusar propostas de caráter preventivo, terapêutico ou diagnósticos que afetem sua integridade físico-psíquica ou social (2).

O consentimento livre e esclarecido pode ser compreendido como expressão máxima do princípio da autonomia do paciente, tendo em vista que deve ser concedido com base na informação reais. O respeito à vontade do paciente, por seu direito de se autogovernar, ficará somente na teoria caso não seja concedido ao paciente as informações necessárias à real consecução da opção livre (7).

A ideia de consentimento livre e esclarecido requer um posicionamento ativo dos profissionais de saúde, com atitudes a estimular o paciente a perquirir, manifestar suas expectativas e preferências aos profissionais de saúde (23).

O paciente deve ter à disposição todos os dados relevantes e necessários para que possa decidir conscientemente. Pontua-se que a informação prestada pelo profissional de saúde não pode vir revestida num discurso hermético e científico, incompreensível ao enfermo, mas deve ser transmitida de forma adaptada às suas circunstâncias culturais e psicológicas. Esse dever de informar gera para o médico a obrigação jurídica de se fazer claro e coerente, equilibrando as partes da relação (7).

Por ter um papel significativo, o paciente tem o dever de fornecer informações necessárias para que o profissional de medicina averigue as soluções mais adequadas para sua patologia. Compete ao paciente informar adequadamente o seu médico, na medida em que o detalhamento dos fatos relacionados à sua história possa concorrer diretamente para 
uma tomada de decisão adequada. O médico, enquanto técnico, precisa munir-se de informações precisas para decidir como proceder.

Tomadas as devidas providências para auferir um consentimento livre e esclarecido de um paciente autônomo, os riscos que envolvem a relação médico-paciente podem ser reduzidos, tendo em vista que todas (ou quase todas) as informações necessárias foram fornecidas e as consequências daquela decisão já foram analisadas minunciosamente.

Ocultar dados do paciente ou pelo paciente pode implicar em consequências desastrosas.

\section{A informação adequada como elementar à compreensão recíproca}

Ao se falar em reconhecimento da autonomia do paciente, em termos de consentimento informado, é de suma importância salientar que tudo isso é legitimado pela efetiva compreensão pelo enfermo da realidade fática.

Compreensão, segundo Piaget (24), é o segundo estágio do conhecimento, que ocorre quando o indivíduo se apropria da informação (25). Reduzir o conteúdo do consentimento à forma escrita não é suficiente para afirmar que um paciente foi devidamente informado. Não se alcança o dever de informar apenas com um documento escrito, faz-se necessário que o consentimento livre e esclarecido tenha alcançado seu objetivo máximo a compreensão efetiva (18).

Necessário observar as situações individuais que diferenciam pacientes a partir de seus contextos de vida, como as condições socioeconômicas, regionais, o grau de escolaridade, com o objetivo de considerar as vulnerabilidades relacionadas ao processo de compreensão das informações deflagradas (18).

Tanto o médico como o paciente encontram-se na condição de explicar e compreender a si mesmos e ao outro. Na medida em que o médico assimila e assume a compreensão das informações fornecidas pelo paciente e dele se aproxima, recorre às várias fontes de explicação e entendimento da situação, inclusive a sua própria história. (26)

Em pesquisa, Andrea Caprara (27) concluiu que 39,1\% dos médicos não explicam de forma clara e compreensiva a realidade fática ao paciente, bem como em $58 \%$ das consultas o médico não verifica o grau de entendimento do paciente sobre o diagnóstico dado. Os médicos, em $53 \%$ das consultas, não verificam a compreensão do paciente sobre as indicações terapêuticas (27). 
Na relação médico-paciente, a autonomia dos participantes é a base ética e jurídica da legitimidade, devendo-se implementar o diálogo, a cognição crítica, compreensão e a escolha (3). Por outro lado, cabe ao paciente pontuar, perante o médico, todas as informações concernentes à sua vida, detalhando situações que possam influenciar na patologia, necessárias à decisão técnica adequada.

O profissional de medicina e o paciente possuem corresponsabilidade na estruturação de uma relação segura, fincada na informação e sua necessária compreensão, na confiança e na boa-fé, elementos que possuem como pressuposto o dever de informar.

\section{Conclusão}

O exercício da autonomia possui como pressuposto a informação, o conhecimento e sua compreensão. O paciente tem o direito de ter à disposição todo e qualquer dado relevante para que possa, livre e conscientemente, decidir, bem como o médico também tem o direito de ser munido de toda e qualquer informação relacionada ao histórico da doença vivenciada pelo paciente.

Observa-se uma necessidade crescente em desenvolver uma relação aberta, com dever mútuo de informação por ambas as partes na relação médico-paciente, que possibilite ao enfermo sentir-se à vontade para expor suas ideias, conflitos e desejos e que esses sejam inteiramente compreendidos pela parte interlocutora. Da mesma forma, o médico deve se certificar que o seu paciente obteve todas as informações necessárias para a formação de sua convicção e que foram, de fato, compreendias.

A omissão de informações pertinentes ao processo decisório ou a sua não compreensão concreta pelos componentes dessa relação pode interferir vertiginosamente na decisão acatada, limitando a autonomia, tanto do enfermo, como do profissional. As decisões poderiam ser diversas daquela tomada, caso conhecessem o que foi ocultado.

Quando a informação e a compreensão não se fazem plenamente presentes, emerge a tendência em judicializar a relação, sucedendo-se mais ações judiciais. Hoje, é possível dizer que parte do número de ações judiciais que envolvem médicos e pacientes tem origem na conformação inadequada do dever de informar, seja por equívoco do profissional ou por equívoco do paciente. Propõe-se, então, repensar a importante dimensão da informação e da sua consequente compreensão, que devem ser protagonistas para o sucesso da relação médico-paciente. 


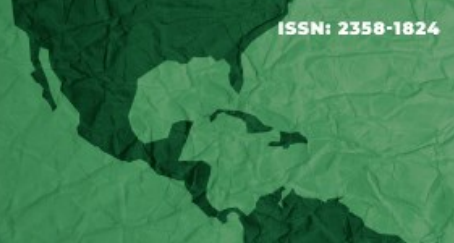

\section{Referências}

1. Goldim JR, Francisconi Carlos F. Modelos de Relação Médico-Paciente [Internet]. [Citado em 05 fev. 2021] Disponível em: https://www.ufrgs.br/bioetica/relacao.htm\#Veatch

2. Conselho Federal de Medicina. Iniciação à Bioética. Brasília (DF): Conselho Federal de Medicina; 1998 [citado em 05 fev. 2021]. Disponível em:

https://portal.cfm.org.br/images/stories/biblioteca/iniciao\%20\%20biotica.pdf

3. Beauchamp TL, Childress JF. Princípios de ética biomédica. São Paulo: Loyola; 2002.

4. Silva JAC. Autonomia versus paternalismo médico: perfil bioético dos egressos do laboratório de cirurgia experimental do curso de medicina da UEPA [Tese online]. Porto, Portugal: Faculdade de Medicina, Universidade do Porto; 2013 [citado em 05 fev. 2021]. Disponível em: https://repositorio-aberto.up.pt/bitstream/10216/70573/2/29062.pdf

5. Salles AA. Transformações na relação médico-paciente na era da informatização. Rev. bioét. (Impr.) [Internet]. 2010 [citado em 05.fev.2021];18(1):49 - 60. Disponível http://revistabioetica.cfm.org.br/index.php/revista_bioetica/article/viewFile/535/521

\section{Bauman Z. Modernidade Líquida. Rio de Janeiro: Zahar; 2001.}

7. Fabbro L. Limitações Jurídicas à Autonomia do Paciente. Rev. bioét. 1999 [citado em 05 fev. 2021];7(1). Disponível em:

http://revistabioetica.cfm.org.br/index.php/revista_bioetica/article/view/286

8. Brasil. Lei $n^{\circ}$ de 10 de janeiro de 2002. Código Civil Brasileiro [Internet]. 2002 [citado em 05.fev.2021]. Disponível em:

http://www.planalto.gov.br/ccivil_03/leis/2002/L10406compilada.htm

9. Brasil. Resolução n 2.232, de 17 de julho de 2019 [Internet]. Estabelece normas éticas para a recusa terapêutica por pacientes e objeção de consciência na relação médicopaciente. [acesso 05.fev.2021]. Disponível em: https://www.in.gov.br/en/web/dou//resolucao-n-2.232-de-17-de-julho-de-2019-216318370? fbclid=IwAR2QOo56NDTaMMBnKvnTHXWYEuQAsqw4xZZYnoICIFw6a8Yjus7vrEcL00

10. Filho JM, Hossne WS. A relação médico-paciente sob a influência do referencial bioético da autonomia. Rev. bioét. [Internet]. 2015 [citado em 05.fev.2021];23(2):304-10. Disponível em: http://revistabioetica.cfm.org.br/index.php/revista_bioetica/article/view/1040

11. Chaves C; Rosenvald N; Netto FPB. Curso de Direito Civil. $3^{a}$ ed. Responsabilidade Civil. São Paulo: Atlas; 2015.

12. Beck U. Sociedade de Risco Rumo a uma outra Modernidade. São Paulo: Editora 34 Ltda; 2013.

13. Beck U. Incertezas Fabricadas [Internet]. IHU Online. 2006 [citado em 05.fev.2021]. Disponível em: http://www.ihuonline.unisinos.br/media/pdf//HUOnlineEdicao181.pdf 
14. Tavares FM. Reflexões acerca da latrogenia e Educação Médica. [citado em 05.fev.2021]. Disponível em:

https://www.scielo.br/scielo.php?script=sci_arttext\&pid=S0100-55022007000200010

15. As principais transformações na evolução médica. Blog Telemedicina Cardiológica. 2016[citado em 05.fev.2021]. Disponível em: https://www.blog.tmebr.com/as-principaistransformacoes-na-evolucao-da-medicina/

16. Ferrer JJ, Álvarez JC. Para Fundamentar a Bioética. São Paulo: Editora Loyola; 2005.

17. Almeida JLT. Da Moral Paternalista ao Modelo de Respeito à Autonomia do Paciente: os Desafios para o Ensino da Ética Médica. Rev bras educ med [Internet]. 2000 [citado em 05 fev. 2021];24(1):27-3. Disponível em:

https://repositorio.ucb.br:9443/jspui/bitstream/123456789/7750/1/Da\%20Moral\%20Paternali sta\%20ao\%20Modelo\%20de\%20Respeito\%20\%C3\%A0\%20autonomia\%20do\%20pacient e....pdf

18. Rocha, EGFM. Direito à verdade e autonomia da vontade no enfermo. De jure: Revista Jurídica do Ministério Público do Estado de Minas Gerais [Internet]. 2007 [citado em 05.fev.2021]. Disponível em:

https://bdjur.stj.jus.br/jspui/bitstream/2011/27759/direito_verdade_autonomia_vontade.pdf

19. Conselho Federal de Medicina. Código de Ética Médica. 2010 [citado em 05.fev.2021]. Disponível em:

https://portal.cfm.org.br/images/stories/biblioteca/codigo\%20de\%20etica\%20medica.pdf

20. Meirelles ATA. A informação na relação médico-paciente: o delineamento da Obrigação mútua face ao argumento da vulnerabilidade. In: Biodireito e direitos dos animais [Internet]. XXVII Encontro Nacional do Conpedi; Salvador; 2018. [citado em 05.fev.2021]; [p. 8-24]. Disponível em:

http://conpedi.danilolr.info/publicacoes/0ds65m46/kz37jz13/kIL5YD8yCe3ObVLU.pdf

21. Costa, Eliane; Machado RR; Koerich MS. Ética e bioética: para dar início à reflexão. exto \& Contexto-Enfermagem [Internet]. 2005 [citado em 05.fev.2021];14(1):106-110. Disponível em: http://www.scielo.br/pdf/tce/v14n1/a14v14n1

22. Chaves C, Rosenvald N. Curso de Direito Civil. $4^{a}$ ed. Contratos. São Paulo: Atlas; 2015.

23. Fortes PAC. Reflexões sobre a Bioética e o Consentimento Esclarecido. Rev. Bioética. [Internet]. 2009 [citado em 05.fev.2021];2(2). Disponível em:

http://revistabioetica.cfm.org.br/index.php/revista_bioetica/article/view/458/341

24. Jacob, MS. El menor maduro. Bol Pediartr. [Internet]. 2005 [acesso

05.fev.2021];45(193):158. Disponível em:

http://www.sccalp.org/boletin/193/BolPediatr2005_45_156-160.pdf

25. Goldim JR. Compreensão [Internet]. 2020 [citado em 05.fev.2021]. Disponível em: https://www.ufrgs.br/bioetica/compreen.htm 
26. Caprara A, Franco ALS. A Relação paciente-médico: para uma humanização da prática médica. Cadernos de saúde pública [Internet]. 1999 [acesso 05 fev. 2021];15(3):647-654. Disponível em: https://www.scielo.br/scielo.php?script=sci_arttext\&pid=S0102311X1999000300023

27. Caprara A, Franco ALS. A relação assimétrica médico-paciente: repensando o vínculo terapêutico. Ciência \& saúde coletiva [Internet]. 2004 [citado em 05 fev. 2021];9(1):139146. Disponível em: https://www.scielo.br/scielo.php?pid=S1413$81232004000100014 \&$ script=sci_abstract\&tlng=pt.

\section{Colaboradores}

Araújo ATM contribuiu para a concepção/desenho do artigo e revisão crítica do conteúdo. Fernandes LS contribuiu com a análise e interpretação de dados, redação do artigo e aprovação da versão final a ser publicada.

\section{Como citar este artigo}

Araújo ATM, Fernandes LS. Liberdade decisória do médico e compreensão pelo paciente: o dever recíproco de informação como pressuposto fundamental. Cadernos Ibero-Americanos de Direito Sanitário. 2021 jan./mar.;10(1):149164.

https://doi.org/10.17566/ciads.v10i1.645 